in vivo $34: 965-972(2020)$

doi:10.21873/invivo.11864

Review

\title{
Laparoscopic and Robotic Management of Ureteral Stricture in Adults
}

\author{
FILIPPOS KAPOGIANNIS ${ }^{1,2}$, ELEFTHERIOS SPARTALIS ${ }^{2,3}$, KONSTANTINOS FASOULAKIS ${ }^{1}$, \\ GERASIMOS TSOUROUFLIS $^{2,3}$, DIMITRIOS DIMITROULIS ${ }^{2,3}$ and NIKOLAOS I. NIKITEAS 2,3 \\ ${ }^{1}$ Department of Urology, Hippokrateion Hospital, Athens, Greece; \\ ${ }^{2}$ Hellenic Minimally Invasive and Robotic Surgery (MIRS) Study Group, Athens Medical School, \\ National and Kapodistrian University of Athens, Athens, Greece; \\ ${ }^{3}$ Second Department of Propaedeutic Surgery, Laiko Hospital, Athens Medical School, \\ National and Kapodistrian University of Athens, Athens, Greece
}

\begin{abstract}
Background/Aim: The aim of this review was to provide an update on the status of minimal invasive treatment of ureteral stricture either with a laparoscopic or robotic surgery. Materials and Methods: Eligible studies, published until November 2019 were retrieved through Medline, Cochrane and Pubmed databases. Predetermined inclusion and exclusion criteria were used as selection method for data synthesis and acquisition. The study was performed in accordance with the PRISMA statement. Results: A total of 19 retrospective studies met the inclusion criteria. All of them demonstrated the safety, feasibility and success of both laparoscopic and robotic ureteral reconstruction. Individual case series or cumulative comparison analysis of the available studies showed at least equivalent success rates and a trend favoring laparoscopic and robotic groups in terms of estimated blood loss and length of hospital stay to the detriment of longer operative times and possibly higher cost. Conclusion: Current evidence suggests the effectiveness, safety and increasing incorporation of minimally invasive techniques for complex stricture repair and reconstruction.
\end{abstract}

A ureteral stricture is characterized by a narrowing of the ureteral lumen, often causing functional obstruction in the

This article is freely accessible online.

Correspondence to: Filippos Kapogiannis, Department of Urology, Hippokrateion General Hospital Athens, Vas. Sofias Ave. 114, Athens 11527, Greece. Mobile: +30 6934571924, e-mail: kapogiannis.phil@gmail.com

Key Words: Ureter, stricture, reconstruction, laparoscopic, robotic, systematic review. flow of urine. When this occurs, urine backs up into the kidney and may cause pain, urinary tract infections, or kidney failure. Management of strictures not amenable to endoscopic treatment involves ureteral reconstruction, which still remains a challenging therapy option. During the past three decades, the field of minimally invasive surgery, especially in urology, has brought major changes in treatment strategies, firstly with laparoscopy, and more recently with robotic surgery. The aim of our study was to provide an outline of the increased adoption of these advancements which although not mature seem to provide encouraging results.

\section{Materials and Methods}

Evidence synthesis. Eligible studies, published until November 2019, were retrieved through Medline, PubMed, and Cochrane databases by applying predetermined inclusion and exclusion criteria and using the following search terms: "ureter" and/or "stricture", "stenosis" or "obstruction" combined with the terms "reconstruction" or "reimplantation" "laparoscopic" or "robotic". Publications on laparoscopic and robotic surgeries, carried out in different ureteral reconstructions and of any study design, including case series and comparative studies, were included. The studies were limited to adult humans and the English language. The Authors independently performed abstract selection followed by full-text screening and excluded articles referring only to endourology or open surgery, pediatric population, congenital causes, fistulas, and case reports. The study was performed in accordance with the PRISMA statement.

\section{Results}

The search strategy identified 123 articles. Of these articles, 24 were excluded after identification of duplicates. Another 23 studies were not in the English language or referred to a 


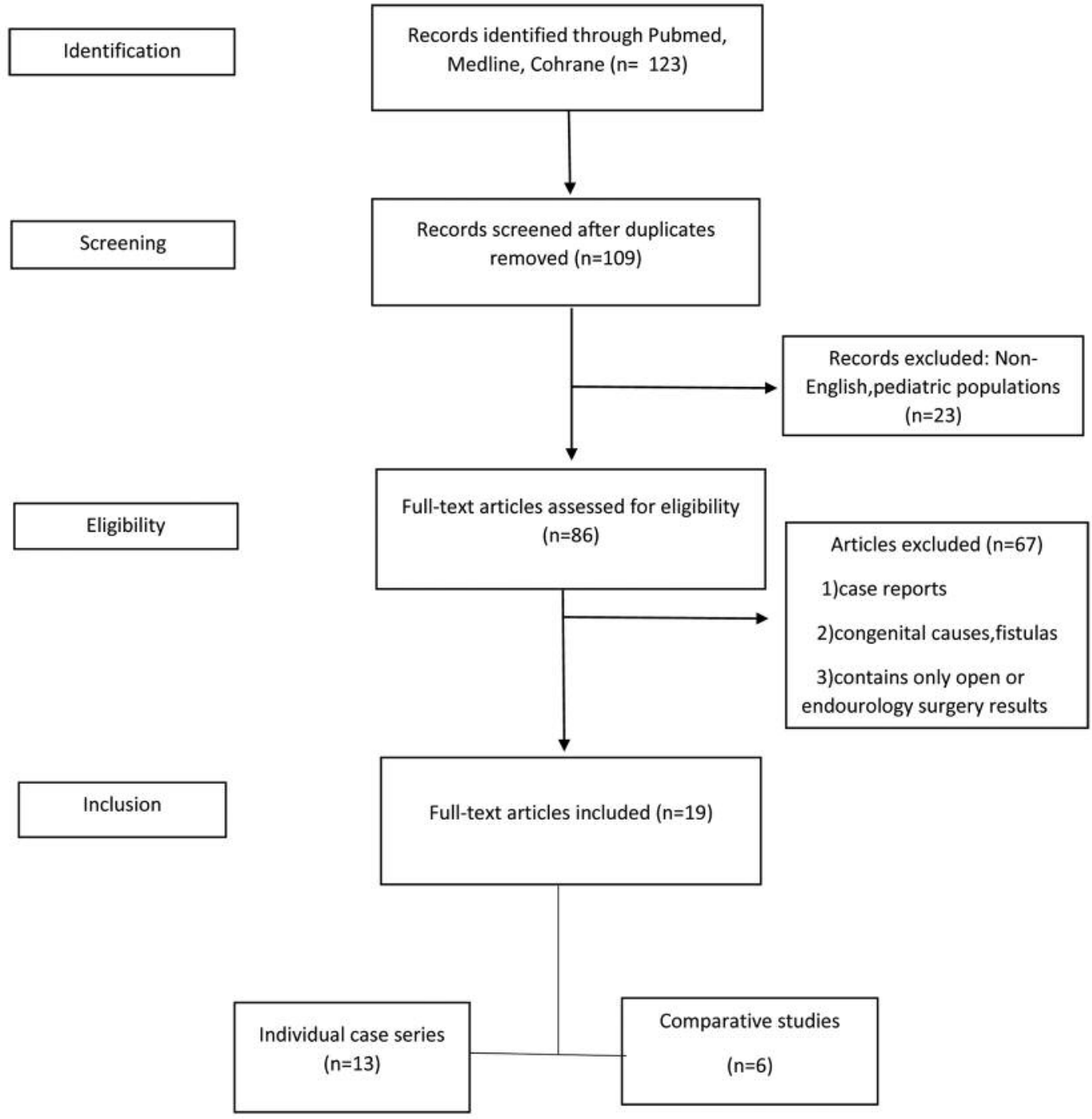

Figure 1. PRISMA four-phase flow diagram of search yield, screening and inclusion steps.

pediatric population and did not fulfill the predetermined criteria for selection. There were, thus, 86 articles selected for full-text review. Following the full-text review, 67 of these were also excluded as they were not relevant or matched exclusion criteria. Finally, 19 articles were included in this study, of which 13 were case series and six were comparative studies. The flowchart of the selected studies is presented in Figure 1.

Incidence. Excluding congenital ureteral strictures commonly located at the ureteropelvic junction, benign pathology and iatrogenic trauma represent the most common causes $(80 \%)$ of stricture formation (1). Another $15 \%$ are characterized as idiopathic and the rest are of malignant origin. Gynecological procedures account for the majority of iatrogenic injuries (70\%), followed only by colorectal ones. They are observed invariably with any type of treatment method i.e. open, endoscopic, laparoscopic or robotic. The aetiological mechanism involves ligation or kinking with a suture, crushing from a clamp, partial or complete transection, thermal injury and ischaemia from devascularization (2). Although incidence of ureteric injuries is under-reported, it is assumed that in the last 20 years, the rates of iatrogenic trauma have decreased or at least remained stable due to improvements in techniques, instruments and surgical experience (3).

Diagnosis. A high degree of suspicion is required by the surgeon since most injuries are not diagnosed intraoperatively. If a retrograde pyelogram cannot be performed, then the 
preferred imaging technique is a triple-phase, contrastenhanced computed tomography with delayed images in the excretory phase for optimal visualization of the relevant anatomy as well as for location of extravasated urine (4). Clinical diagnosis is often helpful, especially postoperatively, with patients reporting symptoms such as pyrexia, haematuria, dysuria, flank pain, urinary incontinence and signs of peritonitis or sepsis (5). In cases of late recognition, the estimation of the function of the affected renal unit is often advocated, principally for medico-legal reasons.

Management. Stricture management depends on many parameters, the most important being its nature, severity, length and location. Due to late diagnosis, a period of 6 weeks to 3 months has been suggested as a reasonable waiting time for reconstruction secondary stricture, unless they are found and repaired the moment they happen which, judging from the outcomes, is the best scenario for patients (6). Although delayed diagnosis adversely affects surgical methods and results (7), ultimate key goals of therapy aim at renal preservation with simultaneous reduction in surgical morbidity irrespective of the time of stricture discovery.

In many cases, endo-urological treatment by internal stenting with or without dilatation is the first choice of intervention performed either retro- or antegradely. The valuable contribution of stents for avoidance of urine extravasation, re-structuring and promotion of ureteral healing must be weighed against a potential aggravation of the severity of the strictures reported by some authors (8). Furthermore, ideal duration and size of stenting are still undetermined.

In case of failure or contraindication of endoscopic therapy, ureteral reconstruction following temporary urine diversion is achieved by open, laparoscopic or robotic techniques. All available modifications are limited by the length of the ureteral stricture itself but are subjected to adherence to specific surgical principles such as: spatulation of ureteral ends, watertight mucosa-to-mucosa anastomosis with absorbable sutures, internal stenting, external drain, debridement of any necrotic tissue and isolation with omentum or peritoneum if possible.

While open surgery remains the mainstay of complex ureteral reconstruction, advances in laparoscopic and robotic technology constantly refine and expand their application as minimal invasive treatment options. Compared with traditional open surgery these techniques have been associated with less postoperative pain, reduced hospitalization, shorter convalescence and improved cosmesis. However, lack of tactile feedback, longer operative time and often cost are disadvantages that haven't been resolved despite growing surgical expertise. Based upon a significant number of studies which are not considered to be controversial, Table I summarizes current approaches for laparoscopic and robotic surgery and treatment of choice stratified by location.
Table I. Summary of robotic and laparoscopic techniques for ureteral stricture management and stratification by location.

\begin{tabular}{lcccc}
\hline Technique & \multicolumn{5}{c}{ Location } \\
\cline { 2 - 5 } & Proximal & Middle & Distal & $\begin{array}{c}\text { Pan } \\
\text { ureter/multiple }\end{array}$ \\
\hline Ureteroureterostomy & $\sqrt{ }$ & $\sqrt{ }$ & $\sqrt{ }$ & \\
Ureteroneocystostomy & & $\sqrt{ }$ & $\sqrt{ }$ & \\
Transureteroureterostomy & $\sqrt{ }$ & $\sqrt{ }$ & & \\
Boari flap & $\sqrt{ }$ & $\sqrt{ }$ & & \\
Psoas hitch & & & $\sqrt{ }$ & $\sqrt{ }$ \\
Appendiceal/buccal & & & & $\sqrt{ }$ \\
mucosa flap & & & & $\sqrt{ }$ \\
Ileal neoureter & & & & \\
Kidney autotransplantation & & & &
\end{tabular}

Laparoscopic approaches.

Laparoscopic uretero-ureterostomy (LUU) and ureteroneocystostomy (LUNC). LUU involves excision of the stenotic segment, spatulation of the ureteral ends and end-to-end anastomosis in either an interrupted or running fashion. Concomitant downward nephropexy may assist in achieving a tension-free anastomosis. In case of difficulty in identifying the ureter, it is suggested to first identify a healthy segment and then to trace the ureter circumferentially towards the diseased segment. The use of near-infrared fluorescent imaging with the aid of clinically available dyes such as indocyanine green and methylene blue is currently being considered as a novel method for ureter visualization (9). Ureteroneocystostomy is the procedure of choice to correct distal ureteral injuries in close proximity to the bladder that measure $3-5 \mathrm{~cm}$. Various approaches to ureteral reimplantation in the adult can be used, such as a modified PolitanoLeadbetter type of repair or an extravesical Lich-Gregoir. In a retrospective review of adults who had undergone ureteroneocystostomy, Stefanovic et al. concluded that there was no difference in preservation of renal function or risk of stenosis with antireflux versus reflux procedures (10).

The first successful LUU was performed in 1992 by Nezhat et al. (11). In the first retrospective, comparative study between open and various laparoscopic procedures, Simmons et al. concluded less estimated blood loss, shorter length of hospital stay in the laparoscopic group but similar patency and complication rates (12). In another comparative analysis, De Cicco et al. suggested similar recurrence ratio between the two groups with success rates reaching $>90 \%$ (13). Yet early reported success can be misleading because recurrent strictures typically develop up to 1 year after surgery.

Recent published experience on LUU or LUNC showed encouraging results although multicenter, randomized and 
with longer follow-up studies are still lacking to strongly support these otherwise technically feasible and safe options that have stood the test of time (14).

Laparoscopic psoas hitch and Boari flap. This procedure includes three major steps: i) Mobilization of bladder to guarantee a tension-free anastomosis; ii) formation of an adequate submucosal tunnel to prevent vesicoureteral reflux; iii) implantation of the ureter into an immobilized part of the bladder to prevent kinking during emptying and filling with urine. While psoas hitch is an almost universal approach of ureteric reimplantation whatever the defect of the distal ureter, an additional Boari flap can be considered as a bridge for ureteric defects $>5 \mathrm{~cm}$. Fugita et al. described three cases using Boari flap without any complications or stricture recurrence observed at a mean follow-up of 11 months (15). Castillo et al. reported 30 cases as part of a large multiinstitutional study. The overall success rate reached $96 \%$ with 32 months follow-up (16). Abraham et al. reported comparable results between early and delayed repair with Boari flap, however, early repair is technically more difficult (17). Recently, Rassweiler et al. compared open and laparoscopic methods, revealing longer operative times, lower estimated blood loss, shorter length of hospital stay for laparoscopy and equivalent success rates (18). Promising results using this technique to repair ureteral defects caused by tuberculosis, malignancy or trauma have also been reported in the literature $(19,20)$. Again, one must bear in mind that, no matter how attractive these procedures might seem, they require extensive time for intracorporeal suturing and thus are not suited for a beginner in laparoscopy.

Laparoscopic transureteroureterostomy (LTUU). This is a reconstructive alternative that can be used for upper and midureteral strictures refractory to conventional surgical therapy. The essential step of the procedure is to transpose one ureter across the midline through a retroperitoneal tunnel and anastomose it to the contralateral one. It is useful in patients who have had previous pelvic surgery that would make a psoas hitch or a bladder flap inadvisable. However, there are certain circumstances whic render LTUU inappropriate: Chronic pyelonephritis, renal stones, idiopathic retroperitoneal fibrosis, previous radiation therapy or urosepsis are some of them. Other limitations are insufficient length of the donor ureter or pathology e.g. reflux to the recipient ureter which will put both kidneys at risk postoperatively. Feasibility of LTUU was first demonstrated by Dechet et al. in nine female pigs (21). Eight of them underwent successful LTUU as judged by excretory urography, retrograde pyelograms and creatinine measurements. The only report on humans is by Piaggio et al., who performed transperitoneal LTUU in three children (22). All cases were carried out successfully with patients having normal kidney function, blood pressure and no significant hydronephrosis at a short follow-up of 6 months. Common drawbacks in accordance with other complex reconstructions are the longer operative time and the need for advanced laparoscopic skills.

Laparoscopic ileal ureter. The surgical principle is to construct a non-refluxing, non-obstructive urinary outflow as soon as possible. An appropriate segment of ileum is anastomosed to the renal pelvis and to the bladder proximal and distal respectively in an isoperistaltic orientation. Gill et $a l$. were the first to report this kind of replacement in an 87year-old man suffering from upper tract transitional cell carcinoma (23). With advanced laparoscopy, more and more cases have been performed in recent years. Stein et al. presented a review of seven patients undergoing open and seven undergoing laparosopic ileal interposition graft. The comparison demonstrated a benefit in narcotic requirement and convalescence in favour of the laparoscopy group (24). This complex reconstruction requires detailed understanding and adequate practice to prevent inherent pitfalls and minimize the -rather high- complication rates.

Laparoscopic kidney autotransplantation (LKAT). Despite having been reported as an effective treatment modality for managing complex renal/ureteral lesions (25), kidney autotransplantation is nowadays underutilized due to high morbidity and relative unfamiliarity of the urological community with renal transplantation. The kidney is harvested laparoscopically and transplanted with the iliac vessels, while the ureter is connected via extravesical ureteroneocystostomy. A study by Gill et al. followed-up four patients who underwent LKAT; one of them suffered from extensive stricture disease. Patients were discharged after an average of 4 days and there were no reported complications (26). Tran et al. evaluated 52 patients after LKAT and reported a success rate of $90 \%$ for an average 6year follow-up (27). Eisenberg et al. followed 15 patients for over 6 months after LKAT; four experienced complications which required surgical intervention (28). Table II summarizes selected studies of laparoscopic ureteral repair.

Robotic reconstruction. Even though laparoscopy offers inherent benefits compared with open surgery, the Da Vinci Surgical System ${ }^{\mathrm{TM}}$ (Intuitive Surgical) has revolutionized reconstructive urology. The rapid uptake of the robotic platform has increased surgeon comfort and has provided technical achievements including 3-D, magnified visualization, enhanced dexterity and ease of intracorporeal suturing. In the past decade, several institutions have implemented new technology and have started to report their initial experience with respect to robotic reconstruction in urology. Despite relative paucity of the existing literature, some of the largest published series are discussed here. 
Table II. Selected series of laparoscopic ureteral reconstruction.

\begin{tabular}{|c|c|c|c|c|c|c|c|c|}
\hline Author (Ref) & Year & $\begin{array}{c}\text { No. of } \\
\text { patients }\end{array}$ & Technique & $\begin{array}{l}\text { Operative } \\
\text { time (min) }\end{array}$ & $\mathrm{EBL}(\mathrm{ml})$ & $\begin{array}{l}\text { Hospital } \\
\text { stay (days) }\end{array}$ & $\begin{array}{l}\text { Follow-up } \\
\text { (months) }\end{array}$ & $\begin{array}{l}\text { Success } \\
\text { rate }\end{array}$ \\
\hline Rassweiler et al. (18) & 2007 & 10 & $\begin{array}{l}\text { Psoas hitch }(n=4) \\
\text { Boari flap }(n=6)\end{array}$ & $254 *$ & $270^{*}$ & $8.2^{*}$ & $17 *$ & $100 \%$ \\
\hline Seideman et al. (29) & 2009 & 45 & $\begin{array}{c}\text { UNC }(n=27) \\
\text { Boari flap }(n=16)\end{array}$ & NR & $150 \ddagger$ & $3 *$ & $25.2 \ddagger$ & $96 \%$ \\
\hline Mereu et al. (30) & 2010 & 17 & UNC & $330^{*}$ & $325^{*}$ & NR & $21^{*}$ & $88 \%$ \\
\hline Castillo et al. (16) & 2013 & 30 & Boari flap & $161^{*}$ & $123 *$ & $4.8^{*}$ & $32 *$ & $100 \%$ \\
\hline Abraham et al. (31) & 2014 & 36 & UNC w/wo Psoas hitch & $187^{*}$ & $120^{*}$ & $4 *$ & $16.3^{*}$ & $100 \%$ \\
\hline Campobasso et al. (32) & 2017 & 23 & UNC & $126^{*}$ & $58^{*}$ & $5.5^{*}$ & $25^{*}$ & $92 \%$ \\
\hline
\end{tabular}

EBL: Estimated blood loss; NR: not reported; UNC: ureteroneocystostomy; w/wo: with/without. *Mean; ${ }^{\ddagger}$ median.

Robotic ureteroureterostomy (RUU). As with open and laparoscopic surgery, lesions up to $3 \mathrm{~cm}$ can also be effectively bridged with robot means. Great care should be taken to preserve as much periureteral tissue as possible in order to maximize ureteral blood supply. Placement of a double-J ureteral stent to span the anastomosis is standard with any ureteral reconstruction procedure. Hemal et al. retrospectively analyzed data of seven patients who had undergone RUU (33). According to the results, mean operative time was 110 min, mean estimated blood loss was $50 \mathrm{ml}$, mean length of hospital stay was 3 days and no recurrences were observed at an average follow-up of 28 months. The largest case series was reported by Buffi et al. (34) and included 17 patients. Mean operative time was 150 min. with a $94 \%$ success rate. No complications greater than grade II were noted. The most recent published comparative study between the two techniques among 126 patients revealed that RUU may be a better choice, with shorter operative time, postoperative hospitalization time and less inflammation (35).

Robotic reimplantation with/without psoas hitch. Whenever a longer defect up to $5 \mathrm{~cm}$ needs to be bridged, ureteral neocystostomy seems to be a realistic option combined with a vesico-psoas hitch if the defect measures up to $10 \mathrm{~cm}$. Implementation of a refluxing or non-refluxing technique is at the discretion of the urologist since studies incorporating open, laparoscopic or robotic surgery have shown similar rates of stenosis and preservation of renal function with either anastomotic approach $(10,36)$. In one of the largest series of robotic upper tract reconstructions, Marien et al. included 31 ureteroneocystostomies via an extravesical approach with $100 \%$ symptomatic and radiographic improvement (37). Another cohort of 45 patients underwent robotic reimplantation with/without psoas hitch, with an overall success rate of $94 \%$, no conversion to open or aborted procedure and major complication rate of $3.6 \%$ (Clavien grade>III) (38)
Robotic Boari flap. Boari flap is a useful treatment option when the diseased segment of the ureter is too long (10-15 $\mathrm{cm})$. It can also be used to bridge uni- or bilateral ureteral structuring. Due to extensive plastic reconstruction of the bladder, a cystogram needs to be performed in advance to outline the bladder contour and determine its capacity. In a study by Musch et al., five cases of Boari flap among other reconstructions were included. Operative time ranged between 230 and $320 \mathrm{~min}$. One case experienced prolonged anastomotic leakage and another bladder wall insufficiency, urinary leakage and peritonitis (39). Do et al. used the Leadbetter-Politano antirefluxing technique in eight patients with minimal blood loss, short catheterization time and low complication rate (40). Stolzenburg et al. replicated the open surgical technique by Überlhör and concluded that is safe and effective for an experienced robotic surgeon (41). Currently, there is no study comparing robotic Boari flap reconstructions. Nevertheless, the robotic approach is associated with the advantages of minimally invasive surgery and the lower technical difficulty compared with laparoscopy.

Robotic ileal ureter. Almost 15 years after the introduction of the Da Vinci robotic platform, Brandao et al. reported the first completely intracorporeal ileal ureter in a patient with multiple strictures (42). An impressive total operating time of 420 min was partially attributed to repeated docking and undocking of the instruments. Ubrig et al. published an initial series of seven patients which is the largest to date (43). Excluding one case which required prolonged stenting, there were no major complications and all patients had a fully functional restored upper tract at the 3-month sonographic, radiographic and renographic follow-up. Common limitations of all the aforementioned studies are the low number of patients, the lack of late follow-up and their retrospective nature. Cases of robotic appendiceal interposition which appear in the literature as an attractive alternative of avoiding bowel anastomosis are sporadic and performed only by experienced surgeons. 
Table III. Selected series of robotic ureteral reconstruction.

\begin{tabular}{|c|c|c|c|c|c|c|c|c|}
\hline Author (Ref) & Year & $\begin{array}{c}\text { No. of } \\
\text { patients }\end{array}$ & Technique & $\begin{array}{l}\text { Operative } \\
\text { time (min) }\end{array}$ & $\mathrm{EBL}(\mathrm{ml})$ & $\begin{array}{c}\text { Hospital } \\
\text { stay (days) }\end{array}$ & $\begin{array}{l}\text { Follow-up } \\
\text { (months) }\end{array}$ & $\begin{array}{l}\text { Success } \\
\text { rate }\end{array}$ \\
\hline Hemal et al. (33) & 2010 & 15 & $\begin{array}{l}\mathrm{UNC}(\mathrm{n}=8) \\
\mathrm{UU}(\mathrm{n}=7)\end{array}$ & $138^{*}$ & $98^{*}$ & $2.4^{*}$ & $13.5^{*}$ & $100 \%$ \\
\hline Fifer et al. (38) & 2014 & 50 & $\begin{array}{c}\text { UNC }(n=45) \\
\text { UU }(n=5)\end{array}$ & $233^{\ddagger}$ & $50 \ddagger$ & $1.6^{\ddagger}$ & $6^{\ddagger}$ & $95 \%$ \\
\hline Marien et al. (37) & 2015 & 250 & $\begin{array}{c}\text { UU }(n=8) \\
\text { UNC }(n=28) \\
\text { Psoas hitch }(n=26)\end{array}$ & $260^{*}$ & $101^{*}$ & $3 *$ & $10.8^{*}$ & $100 \%$ \\
\hline Stolzenburg et al. (41) & 2016 & 11 & Boari flap & $167^{*}$ & $155^{*}$ & NR & $15.2 *$ & $100 \%$ \\
\hline Buffi et al. (34) & 2017 & 39 & $\begin{array}{c}\mathrm{UNC}(\mathrm{n}=21) \\
\mathrm{UU}(\mathrm{n}=17)\end{array}$ & $166^{*}$ & NR & $7 *$ & NR & $94 \%$ \\
\hline Masieri et al. (45) & 2019 & 12 & $\begin{array}{l}\text { UNC }(n=6) \\
\text { UU }(n=6)\end{array}$ & $160^{*}$ & NR & $6^{*}$ & $17 *$ & $91 \%$ \\
\hline
\end{tabular}

EBL: Estimated blood loss; NR: not reported UNC: ureteroneocystostomy; UU: ureteroureterostomy. $*$ Mean; ${ }^{\star}$ median.

Robotic autotransplantation. Autotransplantation represents the ultimate way to preserve renal function when complex ureteral, renovascular or malignant pathologies are encountered. Robotic autotransplantation is still in its infancy as only 11 cases have been reported worldwide (seven from Europe, three from the USA, and one from Japan) (44). Despite its undoubted novelty and innovation, it may be too early to judge the promising outcomes and confirm its establishment as a less morbid type of surgery. Table III summarizes selected studies of robotic ureteral repair.

\section{Discussion}

Ureteral strictures are a relative rare but under-reported problem, often resulting from iatrogenic manipulation of the urinary tract. Treatment strategies are multifactorial, mainly depending on the time of diagnosis and extent of the defect. Therapeutic management ranges from an uncomplicated endoscopic approach to next-generation tissue engineering. The decision as to which repair to perform is often made in the operating room when the precise length of stricture and tissue tension can be readily assessed. Historically, open surgery is considered the gold standard repair method, yet it is associated with significant morbidity, complications and prolonged hospitalization. With the impressive implementation of laparoscopic and robotic surgery and the promising results already reported for pyeloplasty, it seems rational to expect similar outcomes following reconstruction of the ureter. Both routes of minimally invasive surgery offer advantages, including enhanced vision, lower blood loss, less pain, improved cosmesis, shorter hospitalization and faster return to work. The risk of complications or adverse incidents is closely correlated with the complexity of the reconstruction: the more advanced the reconstruction, the more considerable the risk. However, adhesion to open surgical principles is of utmost importance in achieving satisfactory outcomes. Reconstruction of the upper urinary tract, whether laparoscopic or robotic, is a technically demanding operation which requires a high degree of laparoscopic skills, a long learning curve and is currently carried out at specialized centers by experienced surgeons. As medical technologies constantly evolve, surgery continues to reshape and adapt to the new era.

\section{Conclusion}

Although the majority of studies regarding minimally invasive reconstruction for ureteric strictures report at least equivalent success rates, it is at least premature to draw a robust conclusion about superiority of the methods and cost-effectiveness in the background of absence of high-quality data. One must acknowledge that reports in the literature are based on primarily retrospective study designs and are heterogeneous, with small populations and a short follow-up period. Promising results of the reported retrospective data require confirmation by future randomized trials in order to create a substantial paradigm shift. While open surgery is traditionally the main player in the field of reconstructive urology, gradually replacing conventional laparoscopy, robotics might even come to challenge what is established as the gold standard approach to managing a complex stricture in the near future.

\section{Conflicts of Interest}

The Authors report no conflicts of interest.

\section{Authors' Contributions}

Concept and study design: FK, ES and NN. Methods: FK, GT and NN. Results, analysis and conclusions: FK, ES and DD. Article preparation: FK and ES. All Authors read and approved the final version of this article. 


\section{References}

1 Elliott SP and McAninch JW: Ureteral injuries: External and iatrogenic. Urol Clin North Am 33(1): 55-66, vi, 2006. PMID: 1648280. DOI: $10.1016 /$ j.ucl.2005.11.005

2 Delacroix SE, Jr. and Winters JC: Urinary tract injures: Recognition and management. Clin Colon Rectal Surg 23(2): 104 112, 2010. PMID: 21629628. DOI: 10.1055/s-0030-1254297

3 Burks FN and Santucci RA: Management of iatrogenic ureteral injury. Ther Adv Urol 6(3): 115-124, 2014. PMID: 24883109. DOI: $10.1177 / 1756287214526767$

4 Engel O, Rink M and Fisch M: Management of iatrogenic ureteral injury and techniques for ureteral reconstruction. Curr Opin Urol 25(4): 331-335, 2015. PMID: 26049877. DOI: 10.1097/MOU.0000000000000175

5 Gild P, Kluth LA, Vetterlein MW, Engel O, Chun FKH and Fisch $\mathrm{M}$ : Adult iatrogenic ureteral injury and stricture-incidence and treatment strategies. Asian J Urol 5(2): 101-106, 2018. PMID: 29736372. DOI: 10.1016/j.ajur.2018.02.003

6 Ambani SN, Skupin P, Malaeb BS, Barboglio-Romo P and Stoffel JT: Does early ureteroneocystostomy after iatrogenic ureteral injury jeopardize outcome? Urology, 2019. PMID: 31751624. DOI: 10.1016/j.urology.2019.09.056

7 Ghali AM, El Malik EM, Ibrahim AI, Ismail G and Rashid M: Ureteric injuries: Diagnosis, management, and outcome. J Trauma 46(1): 150-158, 1999. PMID: 9932699. DOI: 10.1097/00005373-199901000-00026

8 Yossepowitch O, Lifshitz DA, Dekel Y, Gross M, Keidar DM, Neuman M, Livne PM and Baniel J: Predicting the success of retrograde stenting for managing ureteral obstruction. J Urol 166(5): 1746-1749, 2001. PMID: 115586215.

9 Slooter MD, Janssen A, Bemelman WA, Tanis PJ and Hompes R: Currently available and experimental dyes for intraoperative near-infrared fluorescence imaging of the ureters: A systematic review. Tech Coloproctol 23(4): 305-313, 2019. PMID: 31030340. DOI: 10.1007/s10151-019-01973-4

10 Stefanovic KB, Bukurov NS and Marinkovic JM: Non-antireflux versus antireflux ureteroneocystostomy in adults. Br J Urol 67(3): 263-266, 1991. PMID: 2021812. DOI: 10.1111/j.1464410x.1991.tb15131.x

11 Nezhat C, Nezhat F and Green B: Laparoscopic treatment of obstructed ureter due to endometriosis by resection and ureteroureterostomy: A case report. J Urol 148(3): 865-868, 1992. PMID: 1387420 . DOI: 10.1016/s0022-5347(17)36747-2

12 Simmons MN, Gill IS, Fergany AF, Kaouk JH and Desai MM: Laparoscopic ureteral reconstruction for benign stricture disease. Urology 69(2): 280-284, 2007. PMID: 17320664. DOI: 10.1016/j.urology.2006.09.067

13 De Cicco C, Ret Davalos ML, Van Cleynenbreugel B, Verguts J and Koninckx PR: Iatrogenic ureteral lesions and repair: A review for gynecologists. J Minim Invasive Gynecol 14(4): 428435, 2007. PMID: 17630159. DOI: 10.1016/j.jmig.2007.01.003

14 Wang Z, Chen Z, He Y, Li B, Wen Z and Chen X: Laparoscopic ureteroureterostomy with an intraoperative retrograde ureteroscopy-assisted technique for distal ureteral injury secondary to gynecological surgery: A retrospective comparison with laparoscopic ureteroneocystostomy. Scand J Urol 51(4): 329-334, 2017. PMID: 28388304. DOI: 10.1080/21681805.2017.1304989

15 Fugita OE, Dinlenc C and Kavoussi L: The laparoscopic boari flap. J Urol 166(1): 51-53, 2001. PMID: 11435821.
16 Castillo OA, Travassos J, Escobar JF and Lopez-Fontana G: Laparoscopic ureteral replacement by boari flap: Multiinstitutional experience in 30 cases. Actas Urol Esp 37(10): 658662, 2013. PMID: 23916136. DOI: 10.1016/j.acuro.2012.11.017

17 Abraham GP, Das K, Ramaswami K, George DP, Abraham JJ and Thachil T: Laparoscopic reconstruction of iatrogenicinduced lower ureteric strictures: Does timing of repair influence the outcome? Indian J Urol 27(4): 465-469, 2011. PMID: 22279410. DOI: $10.4103 / 0970-1591.91433$

18 Rassweiler JJ, Gozen AS, Erdogru T, Sugiono M and Teber D: Ureteral reimplantation for management of ureteral strictures: A retrospective comparison of laparoscopic and open techniques. Eur Urol 51(2): 512-522; discussion 522-513, 2007. PMID: 16949730. DOI: 10.1016/j.eururo.2006.08.004

19 O'Boyle PJ, Galli EM and Gow JG: The surgical management of tuberculous lower ureteric stricture. Br J Urol 48(2): 101-105, 1976. PMID: 953413. DOI: 10.1111/j.1464-410x.1976.tb02989.x

20 Rafique $\mathrm{M}$ and Arif $\mathrm{MH}$ : Management of iatrogenic ureteric injuries associated with gynecological surgery. Int Urol Nephrol 34(1): 3135, 2002. PMID: 12549636. DOI: 10.1023/a:1021320409583

21 Dechet CB, Young MM and Segura JW: Laparoscopic transureteroureterostomy: Demonstration of its feasibility in swine. J Endourol 13(7): 487-493, 1999. PMID: 10569521. DOI: 10.1089/end.1999.13.487

22 Piaggio LA and Gonzalez R: Laparoscopic transureteroureterostomy: A novel approach. J Urol 177(6): 2311-2314, 2007. PMID: 17509347. DOI: 10.1016/j.juro.2007.02.004

23 Gill IS, Savage SJ, Senagore AJ and Sung GT: Laparoscopic ileal ureter. J Urol 163(4): 1199-1202, 2000. PMID: 10737495.

24 Stein RJ, Turna B, Patel NS, Weight CJ, Nguyen MM, Shah G, Aron M, Fergany AF, Gill IS and Desai MM: Laparoscopic assisted ileal ureter: Technique, outcomes and comparison to the open procedure. J Urol 182(3): 1032-1039, 2009. PMID: 19616806. DOI: 10.1016/j.juro.2009.05.013

25 Alameddine M, Moghadamyeghaneh Z, Yusufali A, Collazo AM, Jue JS, Zheng I, Morsi M, Prakash NS and Gonzalez J: Kidney autotransplantation: Between the past and the future. Curr Urol Rep 19(3): 7, 2018. PMID: 29399714. DOI: 10.1007/s11934-018-0749-4

26 Gill IS, Uzzo RG, Hobart MG, Streem SB, Goldfarb DA and Noble MJ: Laparoscopic retroperitoneal live donor right nephrectomy for purposes of allotransplantation and autotransplantation. J Urol 164(5): 1500-1504, 2000. PMID: 11025691 .

27 Tran G, Ramaswamy K, Chi T, Meng M, Freise C and Stoller ML: Laparoscopic nephrectomy with autotransplantation: Safety, efficacy and long-term durability. J Urol 194(3): 738-743, 2015. PMID: 25801764. DOI: 10.1016/j.juro.2015.03.089

28 Eisenberg ML, Lee KL, Zumrutbas AE, Meng MV, Freise CE and Stoller ML: Long-term outcomes and late complications of laparoscopic nephrectomy with renal autotransplantation. J Urol 179(1): 240-243, 2008. PMID: 18001789. DOI: 10.1016/j.juro. 2007.08.135

29 Seideman CA, Huckabay C, Smith KD, Permpongkosol S, Nadjafi-Semnani M, Lee BR, Richstone L and Kavoussi LR: Laparoscopic ureteral reimplantation: Technique and outcomes. J Urol 181(4): 1742-1746, 2009. PMID: 19233424. DOI: $10.1016 /$ j.juro.2008.11.102

30 Mereu L, Gagliardi ML, Clarizia R, Mainardi P, Landi S and Minelli L: Laparoscopic management of ureteral endometriosis 
in case of moderate-severe hydroureteronephrosis. Fertil Steril 93(1): 46-51, 2010. PMID: 18990377. DOI: 10.1016/j.fertnstert. 2008.09.076

31 Abraham GP, Das K, Siddiaiah AT, Ramaswami K, George PD and Abraham JJ: Laparoscopic reconstruction of ureteral strictures involving solitary renal units- 1 year and 5 year outcomes. J Minim Access Surg 11(4): 236-240, 2015. PMID: 26622112. DOI: $10.4103 / 0972-9941.144095$

32 Campobasso D, Gaston R, Hoepffner JL, Mugnier C and Piechaud T: Long-term results of laparoscopic Lich-Gregoir technique for ureteral reimplantation: Saint Augustin Clinic experience. Int J Urol 24(7): 559-560, 2017. PMID: 28470710. DOI: $10.1111 /$ iju. 13353

33 Hemal AK, Nayyar R, Gupta NP and Dorairajan LN: Experience with robot assisted laparoscopic surgery for upper and lower benign and malignant ureteral pathologies. Urology 76(6): 13871393, 2010. PMID: 20350753. DOI: 10.1016/j.urology. 2010.01.044

34 Buffi NM, Lughezzani G, Hurle R, Lazzeri M, Taverna G, Bozzini G, Bertolo R, Checcucci E, Porpiglia F, Fossati N, Gandaglia G, Larcher A, Suardi N, Montorsi F, Lista G, Guazzoni G and Mottrie A: Robot-assisted surgery for benign ureteral strictures: Experience and outcomes from four tertiary care institutions. Eur Urol 71(6): 945-951, 2017. PMID: 27473298. DOI: 10.1016/j.eururo.2016.07.022

35 Sun G, Yan L, Ouyang W, Zhang Y, Ding B, Liu Z, Yu X, Hu Z, Li H, Wang S and Ye Z: Management for ureteral stenosis: A comparison of robot-assisted laparoscopic ureteroureterostomy and conventional laparoscopic ureteroureterostomy. J Laparoendosc Adv Surg Tech A 29(9): 1111-1115, 2019. PMID: 31314664. DOI: 10.1089/lap.2019.0357

36 Deng T, Liu B, Luo L, Duan X, Cai C, Zhao Z, Zhu W, Wu W and Zeng G: Robot-assisted laparoscopic versus open ureteral reimplantation for pediatric vesicoureteral reflux: A systematic review and meta-analysis. World J Urol 36(5): 819-828, 2018. PMID: 29374841. DOI: 10.1007/s00345-018-2194-x

37 Marien T, Bjurlin MA, Wynia B, Bilbily M, Rao G, Zhao LC, Shah $O$ and Stifelman MD: Outcomes of robotic-assisted laparoscopic upper urinary tract reconstruction: 250 consecutive patients. BJU Int 116(4): 604-611, 2015. PMID: 25682696. DOI: 10.1111/bju.13086

38 Fifer GL, Raynor MC, Selph P, Woods ME, Wallen EM, Viprakasit DP, Nielsen ME, Smith AM and Pruthi RS: Robotic ureteral reconstruction distal to the ureteropelvic junction: A large single institution clinical series with short-term follow up. J Endourol 28(12): 1424-1428, 2014. PMID: 25230048. DOI: $10.1089 /$ end.2014.0227
39 Musch M, Hohenhorst L, Pailliart A, Loewen H, Davoudi Y and Kroepfl D: Robot-assisted reconstructive surgery of the distal ureter: Single-institution experience in 16 patients. BJU Int 111(5): 773-783, 2013. PMID: 23305121. DOI: 10.1111/j.1464410X.2012.11673.X

40 Do M, Kallidonis P, Qazi H, Liatsikos E, Ho Thi P, Dietel A and Stolzenburg JU: Robot-assisted technique for boari flap ureteral reimplantation: Is robot assistance beneficial? J Endourol 28(6): 679-685, 2014. PMID: 24428629. DOI: 10.1089/end.2013.0775

41 Stolzenburg JU, Rai BP, Do M, Dietel A, Liatsikos E, Ganzer R, Qazi H, Meneses AD and Kallidonis P: Robot-assisted technique for Boari flap ureteric reimplantation: Replicating the techniques of open surgery in robotics. BJU Int 118(3): 482-484, 2016. PMID: 27103101. DOI: 10.1111/bju.13502

42 Brandao LF, Autorino R, Zargar H, Laydner H, Krishnan J, Samarasekera D, Haber GP, Kaouk JH, Chalikonda S and Stein RJ: Robotic ileal ureter: A completely intracorporeal technique. Urology 83(4): 951-954, 2014. PMID: 24518286. DOI: 10.1016/j.urology.2013.11.035

43 Ubrig B, Janusonis J, Paulics L, Boy A, Heiland M and Roosen A: Functional outcome of completely intracorporeal robotic ileal ureteric replacement. Urology 114: 193-197, 2018. PMID: 29180072. DOI: 10.1016/j.urology.2017.11.019

44 Decaestecker K, Van Parys B, Van Besien J, Doumerc N, Desender L, Randon C, De Ryck F, Tailly T, Beysens M, Van Haute C, Ponette D, De Man K, Hoebeke P and Vermassen F: Robot-assisted kidney autotransplantation: A minimally invasive way to salvage kidneys. Eur Urol Focus 4(2): 198-205, 2018. PMID: 30093358. DOI: 10.1016/j.euf.2018.07.019

45 Masieri L, Sforza S, Di Maida F, Grosso AA, Mari A, Rosi EM, Tellini R, Carini M and Minervini A: Robotic correction of iatrogenic ureteral stricture: Preliminary experience from a tertiary referral centre. Scand J Urol 53(5): 356-360, 2019. PMID: 31469016. DOI: 10.1080/21681805.2019.1651390
Received January 4, 2020

Revised January 20, 2020

Accepted January 23, 2020 